\title{
Relações entre Visitantes e Visitados: um retrospecto dos estudos socioantropológicos
}

\author{
Relationship between Visitors and Residents: \\ a retrospective of socio anthropological studies
}

Margarita Barretto ${ }^{1}$

RESUMO: Após a Segunda Guerra Mundial, muito foi escrito sobre o potencial do turismo para promover o entendimento entre os povos, mas essa visão não é compartida nem por todas as organizações sociais nem por todos os intelectuais. Este artigo apresenta estudos realizados em diversas partes do mundo que sugerem que a relação entre visitantes e visitados, apesar de ter uma característica comum, qual seja a efemeridade, difere em função de vários fatores condicionantes, tais como diferença social, econômica, cultural e étnica. Também varia em função do comportamento dos turistas, que, por sua vez, está condicionado a outros fatores, como nível educacional e motivação para viajar, e da atitude dos diversos setores da população local, que também está subordinada aos efeitos que o turismo provoca na sua vida cotidiana ao longo do tempo.

PALAVRAS-CHAVE: visitantes e visitados; relações sociais; diferença sociocultural.

ABSTRACT: After World War II, tourism appeared to be a powerful tool for peace and understanding among some official institution, even this vision was not so clear in scientific circles and civil institutions. This article presents several case studies about the relationship between residents and tourists in different countries, showing that, even there is a common ground of

1. Professora do mestrado acadêmico em Turismo da Universidade de Caxias do Sul - UCS; assessora científica do curso de Turismo do Instituto de Educação Superior Luterano de Santa Catarina IELusc. Contato: Rua Francisco Getúlio Vargas, 1130 - 95070-560 - Caxias do Sul - RS; e-mail: mbarrett@ucs.br. 
ephemeral contacts, relations are different depending on social, economic cultural and ethnic conditions, as well as on tourists behavior and residents attitude, which changes through time depending on how tourism interferes in daily life.

KEYWORDS: visitors and residents; social relations; socio cultural differences.

Desde as origens do turismo de massas, na década de 1950, logo depois da Segunda Guerra Mundial, as expectativas em torno do turismo, do ponto de vista cultural, têm estado centradas na sua potencialidade para promover o intercâmbio cultural entre visitantes e visitados, o conhecimento do outro, a consciência da alteridade e, como conseqüência, a paz mundial. Essa potencialidade do turismo foi difundida pela Organização Mundial do Turismo a partir de afirmações realizadas por um dos primeiros teóricos da economia do turismo, W. Hunziker, que entendia que o turismo tornara-se

o primeiro instrumento da compreensāo entre os povos [que] permite o encontro de seres humanos [...] os reúne [...] constitui um dos principais fatores de aproximação entre os povos e, conseqüentemente, da manutenção de relações pacíficas (apud Krippendorf, 2001: 82).

Na década de 1980, ao mesmo tempo que se proclamava ser o turismo uma força para a paz e o entendimento, as organizações religiosas, reunidas na Coalizão Ecumênica do Turismo do Terceiro Mundo, denunciavam os danos provocados por ele, chegando a dizer que "a idéia de que este fenômeno favorece a paz e a amizade entre os povos [é] um mito contemporâneo" (Crick, 1992: 361).

As pesquisas realizadas até o momento não indicam que os objetivos de entendimento e aproximação tenham sido atingidos. Ao contrário, parecem indicar que se repetem, no turismo, velhos problemas que acompanham a história social da humanidade, como o colonialismo cultural e a xenofobia, e que as relações interpessoais acabam seguindo a lógica mercantil, ou seja, são comercializadas como bem de consumo.

O relacionamento entre visitantes e visitados varia de caso para caso, em função de uma série de circunstâncias favoráveis ou desfavoráveis, o que obriga os pesquisadores a terem muita cautela na hora das inferências, evitando generalizações.

Neste trabalho tentaremos traçar um histórico dos estudos do relacionamento entre visitantes e visitados, extraindo esse tópico de muitos estudos sobre impacto cultural realizados em sistemas abertos de turismo, isto é, em lugares onde os turistas circulam. Há poucos estudos realizados em resorts, onde os turistas se relacionam apenas com os prestadores de serviço. Embora seja metodologicamente fácil pesquisar a questão nesses espaços, o maior empecilho tem sido a autorização para fazê-lo.

Finalmente, neste estudo, espera-se não cair no estereótipo - muito difundido em alguns âmbitos acadêmicos - da visão das populações visitadas como vítimas e dos turistas como algozes, optando-se por mostrar como o relacionamento vai sendo negociado entre uns e outros, permeado pela lógica da sociedade de consumo.

\section{Questões conceituais}

O primeiro problema que se apresenta para analisar a relação entre a comunidade visitada e os turistas é o próprio conceito de comunidade. Desde que esse termo supõe uma "associação de pessoas que tem fins ou interesses comuns e se sujeitam a regras específicas" (Kapeluz, 1994: 393), precisamos, em primeiro lugar, definir sobre qual comunidade iremos falar, dentro das sociedades complexas, tendo em conta, também, que o próprio conceito de sociedade está sendo revisto na atualidade em face das novas mobilidades nos espaços reais e virtuais (Urry, 2000).

Os critérios de definição de comunidade podem ser geográficos, assim temos comunidades que correspondem aos limitesterritoriais, e outras que se definem pela cultura, pela função social ou por aspectos das anteriores. Podemos falar de uma comunidade rural, de uma comunidade caiçara, da comunidade dos empresários, da comunidade dos lojistas, de uma comunidade religiosa, política etc. Quando o turismo se desenvolve em lugares pequenos, que ainda apresentam características de comunidade porque seus membros são poucos e mantêm interesses comuns, a tarefa se torna mais simples. Quando analisamos o turismo em sociedades complexas ou grandes cidades, pode-se dizer que há relações diferentes entre diferentes comunidades dessa sociedade e os turistas que a visitam.

De acordo com De Kadt (1979: 50), os encontros entre turistas e população local podem ser categorizados, para fins de análise, em três situações: quando os turistas compram bens ou serviços, quando turistas e residentes compartem espaços ou quando os turistas se dirigem expressamente aos residentes à procura de informações. Para compreender melhor o primeiro caso é preciso ter em conta que o turismo é um ato praticado por pessoas que realizam uma atividade específica de lazer, fora das suas respectivas cidades, e se utilizam, para atingir seus objetivos, de equipamentos e serviços cuja prestação constitui um negócio. A 
comunidade empresarial que negocia - o trade turístico - estabelece com os turistas relações de mercado. O turista é um consumidor e os membros do trade são vendedores de serviços e/ou produtos. A essa relação entre indivíduos (turistas) e um sistema (o dos negócios turísticos) Nash (1989: 44) denominou "transação complexa".

Nos outros casos, com as diversas comunidades que compõem a sociedade mais ampla, o relacionamento será diferente, inclusive em função do tipo de turistas e de condicionantes histórico-culturais e econômicos dessa sociedade receptora. A relação visitante-visitado não pode ser analisada sem referência às estruturas e processos sociais mais amplos aos quais está conectada (cf. Nash, 1989: 45; Pi-Sunyer, 1989: 189).

Quando a sociedade receptora é mais pobre que a dos visitantes, tem menos avanços tecnológicos e ocupa um status inferior no cenário internacional, o relacionamento será assimétrico por questões estruturais. Com a comunidade dos prestadores de serviços, o relacionamento sempre será assimétrico, porque os turistas estão a passeio, enquanto os segundos estão trabalhando para propiciar o bem-estar dos primeiros.

Os exemplos sobre estações de montanha na Suíça, apresentados por Krippendorf (2001: 84), são eloqüentes. Tratando-se de um dos países com maior igualdade social do mundo, era de se esperar que turistas e população local interagissem como hóspedes e anfitriões. Isso parece ser verdade nos casos de turistas muito antigos que visitam o local há muitos anos, mas não se confirma com as grandes massas que começaram a chegar a partir de 1970. As relações são mecânicas e as pessoas cansam de sempre ter de estar disponíveis e alegres. Não há a tensão entre riqueza e miséria que se observa em outras destinações, mas há a tensão entre aquele que está a lazer e aquele que está a trabalho.

Os turistas, por sua parte, também apresentam comportamentos diferentes.

Na década de 1970, o sociólogo israelense Erik Cohen, em estágio nos Estados Unidos, propõe uma série de tipologias turísticas, constituindo-se no primeiro pesquisador a demonstrar que não se deve falar num turista genérico, mas que é preciso diferenciar os turistas quanto a comportamento e motivações em função de características socioeconômicas e psicossociológicas. Para efeito deste estudo é muito útil sua classificação dos turistas em dois grandes grupos, o dos que praticam formas institucionalizadas de turismo (que viajam por intermédio das diversas instituições turísticas para destinos de massa) e o dos que praticam formas não institucionalizadas (que tentam afastar-se das multidões e organizam sua própria viagem) (cf. Cohen, 1972). Esse pesquisador também determinará que diferentes tipos de turistas estabelecem diferentes relações com a comunidade visitada.
Não obstante as diferenças, posteriormente verifica que existem pontos em comum. Assim, Cohen (1984: 379) classifica os encontros entre visitantes e visitados como "essencialmente transitórios, assimétricos e sem repetição, [onde] os participantes procuram gratificação imediata em lugar de continuidade". Para essas afirmações se baseia nos estudos de Smith, Pearce, Knox, Sutton, Van der Berghe, Greenwood, Pi Sunyer e outros cientistas que têm realizado estudos de caso em diversos lugares do mundo. Acrescenta que essa efemeridade das relações é a que propicia a exploração, o engano, a hostilidade e a desonestidade, que são moeda corrente na relação entre turistas e população local justamente porque nenhuma das partes envolvidas se sente comprometida com as conseqüências da sua ação (cf. Cohen, 1984: 379).

Nota, também, que o relacionamento entre os dois sistemas sociais - o nativo e o turístico - muda à medida que a quantidade de turistas aumenta. Por exemplo, a hospitalidade e a reciprocidade, até o sorriso dos prestadores de serviço, são transformadas em mercadoria, encenadas. O crescimento da quantidade de turistas também leva a que estes deixem de ser individualizados aos olhos dos residentes, que passam a relacionar-se não com a pessoa do turista, mas com o estereótipo predominante no imaginário social local a respeito dele (Pi-Sunyer, 1989: 189).

Vários autores têm detectado etapas diferentes no relacionamento entre visitantes e visitados. O estudo mais conhecido é o de Doxey (1976 apud Cohen, 1984: 381; Ruschmann, 1997: 47; Santana, 1987: 95), que desenvolveu um modelo evolutivo da mudança nas atitudes dos locais para com os turistas. Primeiramente, a população local reage com euforia à presença dos turistas, depois seguem-se a apatia e o tédio, e finalmente o antagonismo. Esse modelo, realizado num estudo de caso em Niágara (Canadá), tem sido questionado, em primeiro lugar, porque a etapa de euforia nem sempre acontece, e em segundo, porque a etapa de antagonismo se dá apenas quando o turismo aprofunda ainda mais as diferenças sociais e quando a população local precisa competir contra os turistas por recursos escassos ou por espaço, mas continua tendo validade como marco de referência.

$\mathrm{Na}$ atualidade parece não haver discussão quanto ao fato de que a relação entre visitantes e visitados apresenta graus de conflito que variam, também, em função da visão que a população local tem dos estrangeiros em decorrência de experiências anteriores com forasteiros não turistas, de preconceitos, da rapidez com que acontece o fenômeno de turistificação, da percepção que a população tem dos benefícios econômicos e sociais advindos do turismo e/ou dos custos sociais e ambientais (Gursoy, Jurowski e Uysal, 2002), da competição por recursos naturais ou pelo uso de instalações, e do grau de distância social e econômica entre visitantes e visitados (Robinson, 2001). Ao mesmo tempo, estudos recentes 
continuam a detectar que a relação dos turistas com as comunidades locais é superficial e efêmera quando não se trata do setor dessa comunidade que presta os serviços turísticos (Robinson, 2001: 39).

Essa aparente contradição, de contatos efêmeros mas ao mesmo tempo geradores de conflitos em maior ou menor medida, nos dá a dimensão da complexidade desse relacionamento. O turismo é uma atividade realizada pelos homens em sociedade. Como tal, tem um importante grau de imprevisibilidade, portanto, não podemos generalizar as relações entre visitantes e visitados nem predizer como elas serão em determinado momento e lugar. Cabe a nós apenas registrar como os fatos acontecem e, nesse sentido, trazermos um retrospecto de pesquisas realizadas a partir da década de 1970, chamando a atenção que a maior quantidade de pesquisas focaliza comunidades com poucos habitantes, em ilhas ou lugares afastados dos centros urbanos. Como atestado por Chambers (2000: 58), os antropólogos têm, via de regra, escolhido estudar casos em que a distinção entre população receptora e visitantes é clara.

\section{Uma aproximação histórica}

De acordo com Nash (1996: I), os primeiros estudos específicos focalizando a relação entre comunidade visitada e turista de massa devem-se a Theron Nuñez, que descreveu os impactos do turismo no México num artigo intitulado "Tourism, tradition and acculturation: weekendism in a Mexican village", publicado no Southwestern Journal of Anthropology. No entanto, um retrospecto histórico das relações entre visitantes e visitados a partir do grand tour é apresentado no livro $A$ horda dourada, editado na Inglaterra em 1976, depois traduzido na Espanha pela Editorial Endymion (cf. Turner e Ash, 1991). Seus autores, após uma exaustiva pesquisa em relatos de viagem de personalidades européias, como os escritores Lord Byron, Mark Twain, Robert Browning, Wolfgang Goethe entre outros, demonstram que, embora a relação entre visitantes e visitados tenha adquirido mais características de conflito a partir do surgimento do turismo de massas, a dificuldade no intercâmbio não parece ter sido diferente em formas anteriores de turismo.

Durante os tempos do grand tour, os representantes da aristocracia inglesa visitavam a empobrecida Roma e outras cidades do que posteriormente viria a constituir-se na Itália, por ser a terra onde estavam as ruínas do Império Romano, o que permitia um contato com a história da civilização. Os contatos com as pessoas, no entanto, estavam limitados a nobres em decadência, com os quais os visitantes já tinham relacionamento, e a mulheres e homens que exerciam a prostituição ou que se prestavam como objetos sexuais, mesmo sem remuneração.
Havia inclusive um mercado do amor; os curas e nobres jovens arranjavam encontros entre os estrangeiros abastados e as mulheres da burguesia local. Nem era preciso recorrer às prostitutas (trecho da biografia de Goethe citado por Turner e Ash, 1991: 64)

Quando Thomas Cook começa a incluir membros da burguesia e da classe operária inglesa nos seus tours, há queixas quanto ao desprezo que os turistas sentiam pelas culturas locais. Turner e Ash (1991: 80) citam um trecho de jornal em que o colunista, irlandês queixava de que os turistas zombavam das cerimônias religiosas (a Irlanda é católica, enquanto na Inglaterra predomina o protestantismo através da Igreja Anglicana), ridicularizavam a culinária, criticavam os trajes, o que, conforme o colunista, seria uma afronta.

Se a relação entre visitantes e visitados era distante durante o grand tour, com a padronização das viagens organizadas ficou ainda maior, uma vez que o grupo guiado somente visitava aqueles lugares que a empresa predeterminava, durante um curto período de tempo, no qual obtinha apenas informações superficiais (Turner e Ash, 1991: 85). O cúmulo do desinteresse pelo conhecimento do outro pode ser detectado no auge do turismo de massas, na década de 1960, quando era comum ouvir turistas afirmando que os lugares seriam mais bonitos, "se não fosse pelos habitantes locais" (cf. Turner e Ash, 1991:210).

Do lado da população local também podia ser detectado, naquela década, o pouco desejo de aproximar-se do outro, como no caso de Bali, província da Indonésia caracterizada por uma forte estabilidade cultural, estruturas sociais hereditárias e um sistema religioso em torno do qual gira a sociedade. Por questões históricas, culturais e religiosas, as mulheres "em geral consideram os europeus, no que diz respeito ao contato físico, quase com repulsa, desde que os acham grossos, peludos e malcheirosos" (Turner e Ash, 1991: 236), e a população em geral age como se os estrangeiros não existissem, os considerando "não seres, sujeitos invisíveis, espectros" (Geertz apud Turner e Ash, 1991: 241).

As pesquisas relatadas por De Kadt (1979: 51-52) em resorts do Caribe (que ele classifica como "instituições totais" onde o turista, em média, "passa vinte e duas horas do seu dia") também demonstram o pouco desejo que os turistas tinham por conhecer os habitantes das cidades em que os enclaves se encontrassem. Respostas como "gostaria de conhecer desde que isso não interferisse com as minhas férias" ou "já sei tudo a respeito; li no folheto" são registradas pelos pesquisadores. Não havendo verdadeiros contatos, não há intercâmbio cultural, mas reforço de preconceitos. Como afirma Krippendorf (2001: 87), no modelo do turismo de massas, para os europeus os outros são pobres, mas felizes; sujos; preguiçosos. Para os nativos os turistas são ricos, não precisam trabalhar e vivem de festa em festa. 
As pesquisas de 1970 e 1980 foram realizadas preferencialmente no Caribe, onde a história de relacionamento entre população nativa e estrangeiros é perpassada pela experiência da escravidão. Outros lugares pesquisados foram ilhas do Pacífico, como as Trobriand, onde o vocábulo que definia turistas era sodiya, que queria dizer soldados, pois estes eram os únicos forasteiros que os moradores conheciam. Pesquisas como essas levaram Van den Berghe (apud Crick, 1992: 378), entre outros, a dizer que os nexos entre turistas e locais são uma paródia de relação humana; Buodhiba (apud Crick, 1992: 380) a afirmar que a hospitalidade não passa de uma técnica de vendas; e Turner e Ash (1991: 375-376) a escrever que:

É uma fraude descrever os anfitriōes como seres universalmente amistosos quando na verdade existem abundantes correntes de ressentimento que afloram a todo momento [...] É uma autêntica imoralidade difundir a idéia de que, por ser turista, alguém pode apagar séculos de desconfiança e isolamento.

Um caso emblemático da relação entre visitantes e visitados é dado por Evans-Pritchard (1989) em seu relato sobre o relacionamento entre índios Navajo e Pucblo, ambos norte-americanos, e turistas da mesma nacionalidade. Na época da pesquisa, os turistas demonstravam ignorar tudo sobre os indígenas e estes, cientes desse fato, pregavam peças nos turistas, zombando da sua ignorância sobre a cultura indígena contemporânea, contando piadas a respeito deles e até ridicularizando-os em algumas peças de artesanato.

Esse caso é ilustrativo de uma das contradições fundamentais da relação entre visitantes e visitados, quando os visitados estão em diferentes estágios de acesso à tecnologia e a outros padrões da civilização ocidental. Os turistas esperam encontrar "o primitivo", o "bom selvagem" não "contaminado" pela civilização urbana. Paradoxalmente, os visitados, quanto mais pobres, mais depositam no turismo suas expectativas de progresso, de integração ao processo civilizatório, à economia de mercado:

[...] visto do interior [das comunidades] o turismo representa modernidade e mudança; mas, do exterior, o objeto turístico é visto como exótico, primitivo e imutável (Lanfant, Allock e Bruner, 1995: IX).

A discussão desses problemas em foros internacionais levou a que na década de 1980 a ECTwT (Coalizão Ecumênica do Turismo do Terceiro Mundo) propusesse uma nova ordem turística, explorando outros modelos possíveis, diferentes do turismo de massa internacional, o chamado "turismo alternativo" (Lanfant e Graburn, 1992: 90-91). Esse modelo tampouco tem tido os resulta- dos esperados quanto ao ideal de comunicação e relacionamento entre visitantes e visitados, por várias razões. Uma delas é que continua com a lógica do desenvolvimento internacional que pressupõe o turismo como produto de exportação; a outra é que continua a utilizar as populações locais, desta vez como atraçāo (Lanfant e Graburn, 1992: 112).

\section{Aculturação, intercâmbio cultural e zoológicos culturais}

Os problemas do colonialismo cultural, aplicados à relação entre visitantes e visitados, estão bem ilustrados nos estudos realizados nas Antilhas por Nuñez e Perez (apud Erisman, 1983). Nessas ilhas do Caribe, a relação entre turistas e população local pode ser muito intensa ou nula, dependendo de haver resorts fechados ou de os turistas circularem, entrando em contato com a população. Erisman (1983: 354) cita o exemplo de Porto Rico, onde, nos subúrbios de San Juan, há muita influência cultural dos turistas, enquanto no oeste da ilha essa influência é praticamente inexistente. Varia também em função da classe social dos habitantes locais. A classe dirigente local se relaciona de uma forma, adotando os padrões culturais e de consumo dos turistas até como forma de mobilidade social ascendente.

Algo bem diferente parece acontecer em Bali. De acordo com McKean (1989), os balineses realizaram um processo que consiste na exaltação de formas tradicionais e sua comercialização dentro da racionalidade capitalista, sem perder os significados e as qualidades características. No caso dos souvenirs, os balineses aceitam fazer artesanato adaptado ao gosto e ao poder aquisitivo dos turistas de massa, mas não diminuem a qualidade do artesanato em geral, que é produzido para os deuses. Os balineses souberam difundir sua arte e seu artesanato adaptando-se às regras internacionais de mercado, sem deixar de cultuar suas divindades, de manter seus laços familiares e comunitários, e de respeitar suas crenças. Exigem respeito dos turistas, por exemplo, não permitindo que participem de certas cerimônias, como cremações. Tratam o turista com respeito, procurando apresentar sua cultura de uma maneira cada vez melhor, com o concurso de antropólogos, historiadores e lingüistas. Os turistas valorizam as apresentações culturais e a população jovem reforça sua identidade.

Enquanto o reino do sagrado autentica e legitima o artesanato, a dança e o teatro balineses, estas criaçōes estéticas, simultaneamente recebem estímulo econômico dos turistas. Esta involução ilustra as características peculiares da tradição clássica e da modernidade que se combinam para fortalecer a produtividade cultural balinese e sua identidade (McKean, 1989: 130). 
Um caso bastante semelhante foi observado por Grünewald (2001) entre os índios Pataxó, que afirmaram sua identidade de "índios turísticos" perante os visitantes, relacionando-se com eles profissionalmente. Fabricam um artesanato para exportação que não perde sua autenticidade, embora respeitem em certos aspectos os gostos europeus; ao mesmo tempo, preservam os âmbitos sagrados da cultura mediante a figura do "pajé-para-turistas", com o qual evitam que o verdadeiro pajé seja transformado em atrativo turístico. Isso tem seu paralelo na já mencionada Bali, onde algumas danças são alteradas imperceptivelmente quando apresentadas aos turistas, de forma a preservar o significado religioso destas quando executadas para a própria comunidade. Na comunidade Amish dos Estados Unidos (Dogan, 1989: 223) pode ser observado o mesmo fenômeno.

Outro caso que guarda semelhanças é o estudado por Giovannini Jr. (2001) em Tiradentes. A comunidade católica realiza várias procissões durante a Semana Santa e isso vem atraindo muitos turistas, que participam ativamente, por exemplo, da procissão do Senhor Morto. A procissão do Senhor dos Passos, porém, que é realizada duas semanas antes, é sigilosa, reservada à comunidade nativa - os turistas não são informados a respeito, "é feita com tanto silêncio e mistério que os surpreende na rua” (Giovannini, 2001: 163). Eles podem contemplar, até fotografar, o que dá aos nativos muito orgulho, porém sempre na qualidade de espectadores.

As reações à presença de turistas podem ser diversas mesmo dentro de uma cultura relativamente unificada. O caso dos esquimós, pesquisado por Smith (1989), é emblemático dessa afirmação. Duas comunidades vizinhas, mas com histórias diferentes, a Kotzebue e a Nome, reagiram ao turismo de forma diversa, com diferenças inclusive dentro da própria comunidade. Em Kotzebue, enquanto algumas pessoas se dedicavam a contar, interpretar e recriar a cultura esquimó para os turistas, as comunidades de pescadores procuravam ocultar-se dos visitantes construindo até tapumes para que os turistas não os observassem nas suas fainas de industrialização dos prodtos derivados da caça das baleias. Em Nome, a comunidade escolheu trabalhar em outras indústrias, e fabricar souvenirs de marfim para os turistas, que seriam vendidos em outros lugares, como forma de evitar o contato com os visitantes. O tipo de contato com a comunidade, também neste caso, depende do tipo de turista. Aqueles chamados pela autora de turistas de elite ou alternativos, que podem pagar altos preços e que gostam de abrir seus próprios caminhos, conhecem melhor a comunidade. Os turistas de massa, que viajam dentro da sua "bolha turística" (metáfora usada para definir o pacote turístico com tudo estruturado), não têm oportunidade "de aprender muito sobre a vida de seus compatriotas, os americanos esquimós [portanto] sofrem do etno- centrismo míope amiúde evidente entre os indivíduos dos países industrializados quando visitam os chamados povos primitivos" (Smith, 1989: 82).

Um estudo semelhante ao anterior foi realizado no estado da Carolina do Norte, Estados Unidos, por Peck e Lepie (1989). Três pequenas comunidades adotaram diferentes formas de relacionamento com os turistas. A primeira delas, chamada Oriental, recebia, além de turistas, veranistas e aposentados que fixaram residência. Todos eles foram integrados à comunidade nas diferentes organizações civis, como o Rotary Club. Já na vizinha Bath, comunidade tradicional baseada nas relações de parentesco, estimulava-se os turistas a ficar apenas duas ou três horas. Há duas casas históricas a duas quadras uma da outra, e chegava-se ao cúmulo de aconselhar os turistas a que realizassem o percurso de carro, de forma a não propiciar a interação com os residentes. Na terceira comunidade, Harkers Island, o conflito pela ocupação do espaço entre turistas e residentes chegou a requerer a intervenção da lei, quando turistas ameaçaram atirar nas crianças que entrassem nos terrenos das casas de veraneio para brincar (Peck e Lepie, 1989: 214).

Outro caso interessante de como as comunidades se relacionam de forma diferente com os turistas é representado pelo grupo étnico Kuna, do Panamá, que vem conseguindo manter o turismo sob o controle local, graças também a uma coesa organização social que os diferencia no contexto latino-americano. A atividade turística acontece dentro de limitações territoriais e temporais. Na época da pesquisa ${ }^{2}$, só algumas comunidades Kuna mantinham contato direto com os turistas, e seus membros separavam muito bem o tempo que dedicavam aos visitantes do tempo destinado a atividades pessoais.

Os Kuna recebem bem os visitantes, mas há coisas para fazer, preparar a comida, dar de comer às crianças, portanto, da mesma forma que estão felizes quando [os visitantes] chegam, estão felizes quando os vêem partir (apud Swain, 1989: 90)

Depoimento semelhante encontrou Urbanowicz (1989: 113) na ilha de Tonga, na Polinésia, onde os habitantes estão "extremamente felizes quando os navios aportam nas docas com milhares de passageiros [...] que injetam milhares de dólares na economia durante oito horas [e] estão mais felizes ainda quando os navios partem ao anoitecer".

Isso porque, de um lado, a relação entre visitantes e visitados é de competição por produtos escassos, variável já mencionada na existência de conflitos. Nesse rei-

2. Na atualidade, os Kuna estão enfrentando problemas com o próprio Estado panamenho, que com consórcios internacionais, está propiciando a desapropriação das suas terras. 
no, grande quantidade de alimentos precisa ser importada, em parte para a população local, mas, fundamentalmente, para os turistas, ocasionando aumento dos índices de preços ao consumidor, o que acaba sendo um problema (cf. Urbanowicz, 1989: 111). De outro lado, a ilha foi vendida pelos promotores turísticos como um lugar onde os turistas podem ver a vida autêntica, andar pelasruas, observar e fotografar o cotidiano da população, e os habitantes de Tonga "não toleram mais serem vistos como membros de um zoológico cultural" (Urbanowicz, 1989: 113).

Essa analogia também foi utilizada por Krippendorf (2001: 86) em relação ao que se observa na maior parte das viagens dos europeus para os países do Terceiro Mundo. De acordo com o autor, "o que deveria ser um encontro sucumbe à síndrome do zoológico [onde] o autóctone torna-se um espetáculo e um tema de fotografias".

Casos de hostilidade aberta e de conflito entre moradores locais e turistas, que requereram até intervenção policial, foram comuns na cidade de Florianópolis (Brasil) durante a década de 1990, quando houve uma grande demanda de turismo de sol e praia por parte de turistas de massa provenientes da Argentina. Schmeil (2002) detectou xenofobia por parte dos nativos e desprezo por parte dos turistas, que vinham à procura de um estereótipo de país tropical e mulheres fáceis vendido pelas agências. Detectou também que a própria comunidade de comerciantes do bairro estudado priorizava o atendimento aos turistas, desprezando a população local, que não pagava em dólares, e que todos os nativos, de alguma forma, tentavam explorar os turistas cobrando preços abusivos.

Na mesma ilha, mais ao sul, Oliveira (2003) estudou as representações sociais da população residente a respeito dos turistas, encontrando que, embora as pessoas reconheçam os benefícios econômicos advindos da presença dos visitantes, bem como o estímulo à preservação ambiental provocado pelo turismo, muitas vezes há hostilidade, que pode ser vista nos muros pintados com a frase "fora haule", sendo que a palavra haule é utilizada pelos surfistas nativos para designar os forasteiros.

\section{Ver versus conviver}

Desde que o turismo de massa propicia apenas um "turismo de ver", no qual os turistas visitam exclusivamente os atrativos turísticos, sem tomar sequer conhecimento da população local, uma nova modalidade foi instituída a partir da década de 1970, a de um turismo que propiciaria a possibilidade de convivência com as pessoas dos lugares visitad

ilustra essa nova modalidade. O tour dentro do ônibus foi substituído por pas- seios a pé, nos quais os turistas podiam ter contato com os locais. Só que, neste caso específico, trata-se de uma pseudoconvivência, pois somente muda o atrativo a ser visto; e não pode haver verdadeiro intercâmbio quando um observa o outro como se fosse uma "curiosidade" exposta numa vitrine.

Dizer que formas alternativas de turismo (alternativas ao turismo de massas e ao modelo do resort) promovem o "intercâmbio" é pressupor que o turismo acontece entre iguais, coisa que, na atualidade, vários antropólogos contestam. Dann (1992) demonstra, com um estudo de mais de 500 casos em Barbados, as diferentes reações dos turistas quando convidados a visitar os lares dos moradores locais. Para além da acurada pesquisa, o relato do autor provoca outras reflexões. Relata que os turistas visitam as residências dos nativos por curiosidade para ver como eles vivem, o que lembra o caso contado por Urbanowicz em parágrafos anteriores.

Um estudo conduzido em Zihuatanejo, México, destino de excursionistas de cruzeiros marítimos, demonstra que ainda hoje, apesar de todo o discurso da integração entre visitantes e visitados, os primeiros não se aventuram além de um raio de 200 metros do porto, por temor de se perderem, de não entenderem o idioma ou da violência, temor esse reforçado pela presença ostensiva da polícia turística (Jaakson, 2004: 57).

Mesmo em lugares onde se tenta realmente promover a convivência tem havido percalços. Numa outra ilha da Indonésia, Sulawesi, os funerais foram divulgados pelo próprio Estado como atrativos turísticos, e os turistas passaram a integrar-se aos rituais. O problema que surgiu foi que, de acordo com a tradição, é um dever sagrado da comunidade oferecer (sem retribuição nenhuma) alojamento e abundante comida a toda pessoa que quiser participar de um funeral Essas comunidades só comiam carne de animais destinados ao sacrifício nesses rituais, e a partir do momento que precisaram dividir a ração com os turistas, passaram a privar-se dessa proteína.

Alimentar uma quantidade crescente de turistas "convidados" porque o governo procura estimular o turismo passou a ser uma carga muito grande para os camponeses (Crystal, 1989: 149).

Novamente, vemos aqui a competição por recursos escassos, só que, por causa das características da população, isso não redundou em conflito, apenas em perdas para a comunidade receptora, que não exige pagamento - de vez em quando ganha um porco de alguma operadora turística ou simplesmente vê suas crianças mendigando doces (Crystal, 1989: 166), numa relação totalmente assimétrica,

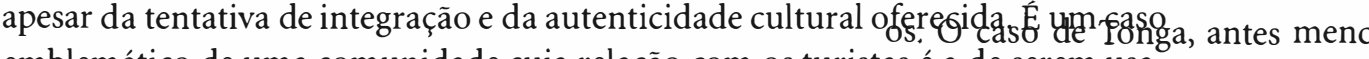
emblemático de uma comunidade cuja relação com os turistas é a de serem usa- 
dos como bem de consumo, nos quais o que é consumido é uma cultura ancestral, sem que os detentores desta aufiram nenhum benefício econômico.

$\mathrm{Na}$ atualidade, o turismo rural desponta como o tipo de turismo que propicia a convivência entre visitantes e visitados. Os resultados são diversos, em função tanto do tipo de turistas quanto da cultura dos proprietários rurais visitados. Há pessoas que se sentem felizes de ter hóspedes permanentemente em casa, mas que se queixam de estarem perdendo o espaço da intimidade familiar, ou de não terem tempo para receber e visitar parentes e amigos, de terem de estar sempre de prontidão para atender os turistas (Costa-Beber, 2004).

$\mathrm{Na}$ Espanha, por exemplo, Agustín Santana ${ }^{3}$ relata que, aos poucos, a oferta de alojamento com famílias camponesas vai cedendo lugar à oferta tradicional de um alojamento separado. A fazenda transformou-se em hotel e agora toma a forma de hotel-fazenda, despojada de suas características originais, por causa das implicaçōes do conviver permanentemente com estranhos dentro de casa.

Essas formas de relacionamento entre visitantes e visitados estão intimamente ligadas a duas questōes que não serão abordadas neste contexto. Uma é a da autenticidade da experiência turística, amplamente debatida a partir da década de 1960. A outra, a reflexividade da vida social moderna, que "consiste no fato de que as práticas sociais são constantemente examinadas e reformadas à luz de informação renovada sobre estas próprias práticas, alterando assim constitutivamente seu caráter" (Giddens, 1991: 45), fenômeno que explica a diversidade das reações de turistas e populações receptoras e os feedbacks diferentes de cada experiência turística.

\section{Conclusão}

Por meio dessas leituras podemos perceber que o relacionamento entre visitantes e visitados apresenta um amplo espectro, variando de uma situação em que praticamente não há contato entre visitantes e visitados, a não ser com os prestadores de serviços turísticos, que é comum nas formas institucionalizadas de turismo e no turismo realizado em grandes centros urbanos, a outra em que os visitantes circulam dentro das comunidades receptoras, algo próprio das formas não institucionalizadas de turismo e de centros urbanos pequenos ou de centros não urbanos. Entre estas, há uma ampla gama de variaçōes nos graus de contato e nos tipos de relaçōes que se estabelecem.

3. Comunicação pessoal.
Hoje está muito claro que, quando Valene Smith deu o título de Anfitriōes e convidados a seu livro - que com o tempo haveria de se transformar numa obra fundamental do pensamento antropológico aplicado ao turismo -, o fez no sentido metafórico. Os moradores dos núcleos receptores não se comportam como anfitriōes, desde que sua receptividade é profissional, e a partir do século XIX, os turistas, muito poucas vezes, são realmente convidados, a não ser por planos de desenvolvimento turístico. Convidados ou não, prevalece o fato de que, do ponto de vista social e cultural, sempre serão forasteiros, e seu relacionamento com as populaçōes receptoras sempre se dará a partir dessa condição.

O turismo, em sentido amplo, é um fenômeno social. Mas em sentido restrito, na perspectiva dos núcleos receptores, é um negócio. Um negócio que vende algo diferente, sim: prazer e lazer, mas que é conduzido pela lógica da sociedade capitalista, pela produtividade e pela lucratividade.

Apesar das poucas pesquisas sistematizadas a respeito, as existentes demonstram que, na verdade, os habitantes dos lugares turísticos que se beneficiam economicamente com a presença dos turistas não estão precisamente interessados em receber os turistas como hóspedes e realizar com eles trocas culturais, mas em receber o dinheiro trazido por eles. Os turistas passam a ser um mal necessário. Mal porque sua presença incomoda. Necessário porque seu dinheiro faz falta. Os turistas, por sua vez, vêm no habitante local apenas um instrumento para seus fins. O grande paradoxo do turismo é que essa atividade coloca em contato pessoas que não enxergam a si mesmas como pessoas, mas como portadoras de uma função precisa e determinada: uns trazem dinheiro com o qual compram os serviços do outro. O primeiro é consumidor, o outro, parte da mercadoria, e é essa a relação que prevalece.

Turistas e população local têm diversos graus de empatia, dentro de um leque que vai da simpatia à hostilidade, passando pela cordialidade profissionalmente trabalhada. A tendência parece ser que os relacionamentos entre visitantes e visitados sejam cada vez mais profissionais, à medida que os serviços turísticos e os próprios turistas se profissionalizam.

\section{Referências bibliográficas}

COHEN, Erik. 1972. Towards a sociology of international tourism. Social Research, v. 39, n. 1, p. 164-172.

1984. The sociology of tourism: approaches, issues and findings. Annual Review of Sociology, v. 10, p. 373-392.

COSTA-BEBER, Ana Maria. 2004. Mudanças socioculturais no turismo rural: o caso de uma pousada familiar. Dissertação (Mestrado em Turismo) - ucs, Caxias do Sul. 
CHAMBERS, Erve. 2000. Native tours: the anthropology of travel and tourism. Illinois: Waveland Press.

CRICK, Malcom. 1992. Representaciones del turismo internacional en las ciencias sociales: sol, sexo, paisaje, ahorros y servilismos. In: JURDAO ARRONES, F. Los mitos del turismo. Madrid: Endymion.

CRISTAL, Eric. 1989. Tourism in Toraja (Sulawesi) Indonesia. In: SMITH, Valene (Ed.). Hosts and guests: the anthropology of tourism. Philadelphia: University of Pennsylvania Press, p. 139-168.

DANN, Graham. 1992. Predisposition toward alternative forms of tourism among tourists visiting Barbados: some preliminary observations. In: SMITH, V. \& EADINGTON, W. R. (Eds.) Tourism alternatives, potential and problems in the development of tourism. Philadelphia: University of Pennsylvania Press, p. 158-179.

DE KADT, Emanuel. 1979. Tourism, passport to development? USA: Oxford University Press.

DOGAN, Hasan Z. 1989. Forms of adjustment. Sociocultural impacts of tourism. Annals of Tourism Research, v. 16, p. 216-236.

ERISMAN, H. Michael. 1983. Tourism and cultural dependency. Annals of Tourism Research, v. 10, n. 3, p. 337-362.

EVANS-PRITCHARD, Deirdre. 1989. How they see us? Native American images of tourists. Annals of Tourism Research, v. 16, p. 89-105.

GIDDENS, Anthony. 1991. As conseqüências da modernidade. São Paulo: UNESP.

GIOVANNINI JR., Oswaldo. 2001. Cidade presépio em tempos da paixão.Turismo e religião: tensão, negociação e inversão na cidade histórica de Tiradentes. In: BANDUCCI JR., Alvaro \& BARRETTO, Margarita. Turismo e identidade local: uma visão antropológica.Campinas: Papirus. p. 149-174.

GRÜNEWALD, Rodrigo de A. 2001. Turismo e o "resgate" da cultura Pataxó. In: BANDUCCI JR., Alvaro \& BARRETTO, Margarita. Turismo e identidade local: uma visão antropológica. Campinas: Papirus. p. 127-148.

GURSOY, Dogan; JOROWSKY, Claudia \& UYSAL, Muzafer. 2002. Actitudes de los residentes: un enfoque de modelización estructural.Annals of Tourism Research en Español, v. 4, n. 1, Jun., p. 63-92.

JAAKSON, Reiner. 2004. Beyond de tourist bubble? Cruise ship passengers in port. Annals of Tourism Research, v. 31, n. 1, p. 44-60.

KAPELUZ. 1994. Diccionario de la lengua española y enciclopédico. Buenos Aires.

KRIPPENDORF, Jost. 2001. Sociologia do turismo: para uma nova compreensão do lazer e das viagens. São Paulo: Aleph

LANFANT, Marie-Françoise; ALLOCK, John B. \& BRUNER, Edward M. 1995. International tourism: identity and change. London: Sage.

LANFANT, Marie-Françoise \& GRABURN, Nelson. 1992. International tourism reconsidered: the principle of the alternative. In: SMITH, Valene \& EADINGTON, William R. Tourism alternatives. Philadelphia: University of Pennsylvania Press.
McKEAN, Philip F. 1989. Towards a theoretical analysis of tourism: economic dualism and cultural involution in Bali. In: SMITH, Valene (Ed.). Hosts and guests: the anthropology of tourism. Philadelphia: University of Pennsylvania Press. p. 119-138.

NASH, Dennison. 1996. Anthropology of tourism. Oxford: Pergamon.

1989. Tourism as a form of imperialism. In: SMITH, Valene (Ed.). Hosts and guests: the anthropology of tourism. Philadelphia: University of Pennsylvania Press. p. 37-54.

OLIVEIRA, Maria Conceição de. 2003. Representações sociais do turismo na praia do Campeche - Ilha de Santa Catarina: por uma abordagem interdisciplinar. Tese (Doutorado Interdisciplinar em Ciências Humanas) - UFSC, Florianópolis.

PECK, John G. \& LEPIE, Alice S. 1989. Tourism and development in three North Carolina coastal towns. In: SMITH, Valene (Ed.). Hosts and guests: the anthropology of tourism. Philadelphia: University of Pennsylvania Press. p. 203-222.

PI-SUNYER, Oriol. 1989. Changing perceptions in a Catalan Resort Town. In: SMITH, Valene (Ed.). Hosts and guests: the anthropology of tourism. Philadelphia: University of Pennsylvania Press. p. 187-199.

ROBINSON, Mike. 2001. Tourism encounters: inter and intra-cultural conflicts and the world's largest industry. In: ALSAYYAD, Nezar (Ed.).Consuming tradition, manufacturing heritage: global norms and urban forms in the age of tourism. London: Routledge. p. 34-67.

RUSCHMANN, Doris. 1997. Turismo e planejamento sustentável: a proteção do meio ambiente. Campinas: Papirus.

SANTANA TALAVERA, Agustín. 1997. Antropología y turismo ¿Nuevas hordas, viejas culturas? Barcelona: Ariel.

SCHMEIL, Lilian. 2002. Alquila-se uma ilha. In: FRIGERIO, Alejandro \& RIBEIRO, Gustavo L. Argentinos e brasileiros: encontros, imagens e estereótipos. Petrópolis: Vozes. p. 7 1-94.

SWAIN, Margaret B. 1989. Gender roles in indigenous tourism: Kuna Mola, Kuna Yala and cultural survival. In: SMITH, Valene (Ed.). Hosts and guests: the anthropology of tourism. Philadelphia: University of Pennsylvania Press. p. 83-104.

TURNER, Louis \& ASH, John. 1991. La horda dorada: el turismo internacional y la periferia del placer. Madrid: Endymion. (Original The golden hordes).

URBANOWICZ, Charles F. 1989. Tourism in Tonga revisited: continued troubles times? In: SMITH, Valene (Ed.). Hosts and guests: the anthropology of tourism. Philadelphia: University of Pennsylvania Press. p. 105-118.

URRY, John. 2000. Sociology beyond societies. London: Routledge.

Recebido em 05/07/2004

Aprovado em 28/08/2004 